\title{
Calling songs of sympatric and allopatric populations of Cicada barbara and $C$. orni (Hemiptera: Cicadidae) on the Iberian Peninsula
}

\author{
Sofia G. SEABRA, Gabriela PINTO-JUMA and José A. QUARTAU
}

Centro de Biologia Ambiental \& Departamento de Biologia Animal, Faculdade de Ciências de Lisboa, Campo Grande, $1749-016$ Lisboa, Portugal; e-mail: sgseabra@fc.ul.pt

Key words. Cicadidae, Cicada barbara, C. orni, cicadas, acoustics, calling song, sympatry, allopatry

\begin{abstract}
Calling songs of the sibling species Cicada barbara and C. orni were studied in sympatric and allopatric populations on the Iberian Peninsula, where the distribution ranges of both species overlap. No difference was found in any acoustic property for the sympatric and allopatric populations of $C$. barbara studied and only one variable (minimum frequency) was significantly different between sympatric and allopatric populations of $C$. orni. No hybrids with intermediate songs were found and no character displacement in the calling song was detected. It is very likely that these species were already considerably differentiated when they met on the Iberian Peninsula. Particularly, premating (or even postmating) isolating mechanisms (according to Mayr's Biological Species Concept) or different specific-mate recognition systems (in the view of the Paterson's Recognition Concept of Species) were most likely already present, which prevented hybridization between this pair of species. It is assumed that the calling songs are the most important premating isolating mechanism corresponding to the specific-mate recognition systems of these species of cicadas.
\end{abstract}

\section{INTRODUCTION}

Cicada barbara Stål and C. orni Linnaeus (Hemiptera, Cicadidae) are a pair of sibling cicada species, very similar in morphology, with only slight differences in external characteristics. Examples are differences in the wing spots (Quartau, 1988; Ribeiro, 1998) and in the male genitalia, namely in the lengths of the pygofer (and its dorsal spine), the tenth abdominal segment and its appendages (which are shorter in C. barbara) and in the width of the shaft of the aedeagus (thinner in $C$. orni) (Quartau, 1988). In contrast, the acoustic signals produced by the males of these two species are distinct, since C. barbara produces a continuous series of pulses without pauses (Boulard, 1982, 1995; Fonseca, 1991; Quartau \& Rebelo, 1994) and C. orni a series of pulses forming echemes alternating with intervals of silence (Popov, 1975; Boulard, 1982; Fonseca, 1991; Quartau et al., 1999, 2000; Pinto-Juma et al., 2005). In addition, sequencing of the $12 \mathrm{~S}$ rRNA mitochondrial gene indicates that these two species constitute distinct evolutionary units (Pinto-Juma et al., unpubl.).

Both C. barbara and C. orni occur in Mediterranean woodland or shrubland, mainly in olive, oak or pine tree groves, but also on other trees and shrubs and even on scattered vegetation in cities (Quartau, 1995). In Corsica C. orni was found by Puissant \& Sueur (2001) on two types of vegetation: either it is 0.5 to $2 \mathrm{~m}$ high with ligneous plants covering more than $60 \%$ of the area or more than $2 \mathrm{~m}$ high with ligneous plants covering more than $40 \%$ of the area. Only C. barbara is present both in North Africa and the Iberian Peninsula. C. orni is distributed in south west, central and eastern Europe, western Asia and the Middle East (Popov, 1975; Quartau \& Fonseca, 1988; Schedl, 1973, 1999). Moreover the Iberian populations of C. barbara are considered by Boulard (1982) to be a sub- species, C. barbara lusitanica Boulard, different from the type subspecies, which only occurs in north Africa $(C$. barbara barbara Stål).

The distribution ranges of $C$. barbara and $C$. orni overlap on the Iberian Peninsula, and males of both species in a few localities can be seen singing on the same trees at the same time. However, there is some seasonal displacement as C. orni emerges earlier in summer (June) than $C$. barbara (July/August). In allopatric populations, the adults of $C$. orni disappear in September/October, whereas in sympatric populations they usually disappear much earlier (August). C. barbara shows less variation: it appears somewhat earlier where it occurs allopatrically than sympatrically but disappears at the same time, in September/October (Ribeiro, 1998; and pers. obs.).

Despite the clear differences in the calling songs of males of C. barbara and C. orni, the structure of the tymbals and mechanism of sound production in these species is similar, as expected in closely related species of the same genus (Fonseca, 1991, 1994). In both species the inward distortion of one of the tymbals (membranes located in the first segment of the abdomen, which are distorted by the tymbal muscles) produces usually three pulses of sound and the outward distortion another pulse, which is usually superimposed on the inward pulses of the other tymbal (Fonseca, 1991). The tymbals alternate in the production of sound.

Males of C. barbara and C. orni sing continuously for hours, usually without changing their location. This pattern of behaviour is described in Cooley \& Marshall (2001), as one extreme in the range of systems found in acoustically signalling insects, and is observed in other species, such as the Neotropical cicada Fidicina mannifera (Cocroft \& Pogue, 1996), the Palaearctic Tibicina species (Quartau \& Simões, 2003; Sueur \& Aubin, 2004) 
and the Australian Cystosoma saundersii (Doolan, 1981). Males of both species of Cicada studied sing during the hottest part of the day, sometimes even at night if temperatures are well above $30^{\circ} \mathrm{C}$.

The calling songs of cicada males are known to attract conspecific females in other species, for example in Pycna semiclara and Azanicada zuluensis (Villet, 1992), in Cystosoma saundersii and Cyclochila australasiae (Daws et al., 1997) and in Magicicada spp. (Cooley \& Marshall, 2001), and are also known to result in the aggregation of males, for example in Azanicada zuluensis (Villet, 1992) and Magicicada spp. (Cooley \& Marshall, 2001).

Experiments on the behaviour of cicadas in general, and C. barbara and C. orni in particular, are difficult in captivity (Fonseca \& Revez, 2002a; Simões \& Quartau, unpubl.). In the field, the males of both species often aggregate on the same trees, with a single male song often eliciting other males to sing. Moreover, females are often seen flying to the trunks or branches of trees where males are singing (pers. obs.). Playback experiments carried out with males of C. barbara (Fonseca \& Revez, 2002a) has shown that females of this species can discriminate conspecific song from that of C. orni, as they respond (by singing) more quickly to the conspecific than heterospecific song. Also, altering the temporal pattern of the calling song of $C$. barbara reduce the response of the males, which do not respond to songs with pauses longer than $30 \mathrm{~ms}$, which is more characteristic $C$. orni song, but respond to a modified $C$. orni song without pauses. No experiments were done yet about species discrimination by females.

Where sibling species occur sympatrically it is possible to address questions about isolation mechanisms and recognition processes. According to the Biological Species Concept, species are isolated from each other by "isolating mechanisms" (Dobzhansky, 1951), which include premating or postmating mechanisms (Mayr, 1948, 1963). According to Dobzhansky (1951), if two incompletely reproductively isolated species meet, after a period of allopatry, the reinforcement of isolating mechanisms might evolve by natural selection to prevent heterospecific matings. Under this scenario, sympatric populations would be expected to show more marked reproductive character displacement in mating mechanisms in comparison to allopatric populations. However, Paterson (1985) criticizes this concept since he considers the premating and postmating isolating mechanisms as effects, not evolving to serve the function of preventing hybridization between species. In his Recognition Concept of Species, species are seen as "that most inclusive population of individual biparental organisms which share a common fertilization system" (Paterson, 1985 p. 25). Speciation is seen by Paterson as an incidental effect resulting from the adaptation of the characters of the fertilization system (or Specific-Mate Recognition System SMRS), among others, to a new habitat. According to the same author, if two populations have interpopulation "sterility" (heterozygote disadvantage) but share a common
SMRS, they cannot coexist, since natural selection will act to eliminate the cause of hybrid disadvantage, in which case, reproductive character displacement is not expected (Paterson, 1985).

Evidence of reproductive character displacement is difficult to find. Marshall \& Cooley (2000) report a case in one pair of north-American cicada species, Magicicada tredecim and $M$. neotredecim. These authors found that M. neotredecim produces higher dominant frequency calls when it occurs sympatrically than allopatrically with $M$. tredecim, but the latter species maintains the same frequency throughout their distribution range. This is the expected pattern if there is a process of reinforcement driven by selection against wasteful heterospecific matings (Marshall \& Cooley, 2000). Alternatively, this character displacement could be viewed as an adaptation of $M$. neotredecim to the acoustic environment created by M. tredecim. In fact, the background noise created by the calling activity of another species may affect the receiver's ability to perceive signals and promote directional selection of the signal produced (Villet, 1995).

In this paper the evidence for hybrids with intermediate characteristics in calling songs between $C$. barbara and C. orni was assessed. Differences between the calling songs of sympatric and allopatric populations of each species on the Iberian Peninsula, particularly, whether the songs were more similar or different when species occurred sympatrically, were also investigated.

\section{MATERIAL AND METHODS}

\section{Field procedures}

Eleven populations of C. barbara and eight of C. orni were sampled on the Iberian Peninsula where these species occurred allopatrically (six for C. barbara and four for C. orni) and sympatrically (five for C. barbara and four for C. orni) (Fig. 1 and Table 1).

Male cicadas were located by their calling songs. Recordings of the acoustic signals were made using a Sony Dat recorder (TCD-D10 ProII; frequency range 20-22000 Hz; sampling frequency $44.1 \mathrm{kHz}$ ) connected to a dynamic Sony F-780 microphone (frequency responses $50-18000 \mathrm{~Hz}$ ). Ambient temperature was taken in the shade at the time of each recording at all localities except Alcalar, Alvor, Monforte, Casalinho and Piedade.

\section{Sound analysis}

Sound recordings were digitized using the software AvisoftSASLab Pro (Specht, 2002) at a sampling rate of $44.1 \mathrm{kHz}$ and a resolution of 16 bits. Time and frequency analysis were performed on one-minute recordings of each individual (whenever possible). Fast Fourier transformation with a resolution of 512 points and a Hamming Window was applied to compute the frequency spectra (Fig. 2). The gross-temporal variables analysed in C. orni were: number and duration of echemes and duration of the interval between them (interecheme interval) (Fig. 2). Echeme rates, periods and ratios echeme/interval were then calculated. Spectrum-based variables analysed for both species were: peak frequency, minimum frequency, maximum frequency, bandwidths, and quartiles (described in Pinto-Juma et al., 2005). In C. orni, all frequency measurements were calculated from the mean spectrum of each echeme. Time and frequency measurements of the echemes were then averaged, and the mean was taken as the value of the variable for each speci- 


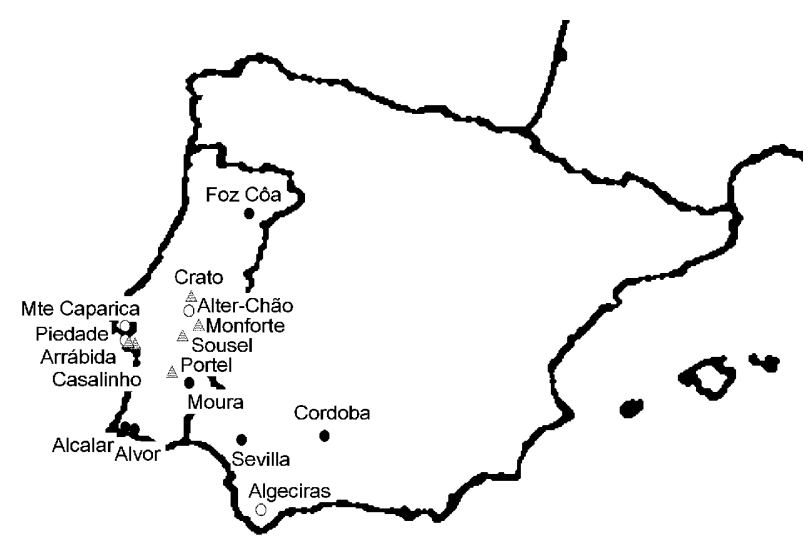

Fig. 1. Allopatric populations of Cicada barbara (dark circles) and C. orni (empty circles), and sympatric populations of both species (triangles) sampled on the Iberian Peninsula

men. A fine-temporal property of the signals, the syllable rate, was also calculated for both species. The number of groups of pulses (syllables) was counted in 30 echemes for $C$. orni (first and last syllables in each echeme were discarded due to their different characteristics - see Fig. 2) and 30 fragments of c. 0.1 $\mathrm{s}$ for $C$. barbara. The average number of syllables per unit of time was calculated for each specimen. These syllable rates correspond to the production of pulses by the two tymbals.

\section{Statistical analysis}

Nonparametric Mann-Whitney tests were used to compare each acoustic variable between species and between sympatric and allopatric populations of each species. Coefficients of variation for each acoustic variable were compared between species using the nonparametric Wilcoxon signed rank test. Spearman nonparametric correlations between ambient temperature and each acoustic variable were also computed for each species. The significance of multiple tests was assessed by reducing the critical P value according to the Dunn-Sidák method (Dytham, $2003)$, from 0.05 to $1-(0.951 / \mathrm{k})$, where $\mathrm{k}$ is the number of tests performed.

Multivariate analysis was applied to the data matrix of 9 acoustic variables (the variables common to both species) measured for 158 individuals, namely a Principal Components Analysis (PCA) and a Discriminant Function Analysis (DFA). PCA is used to reduce a large number of variables to a smaller number of factors (or components), with no need to specify a dependent variable. The percentage of variance explained by each of the components is given, as well as the correlation coefficients between the variables and the components (component loadings). The component scores obtained for the individuals can be used to compare groups (in this case there are four groups: allopatric $C$. barbara, sympatric $C$. barbara, sympatric C. orni and allopatric C. orni) with Kruskall-Wallis and MannWhitney tests. In DFA, on the other hand, groups are determined beforehand. It derives discriminant functions that best separate the groups. The statistical significances of the functions in discriminating the groups are given, as well as the correla-

TABLE 1. Populations of Cicada barbara and C. orni sampled on the Iberian Peninsula in areas where they occurred allopatrically and sympatrically.

\begin{tabular}{|c|c|c|c|}
\hline Localitites & $\mathrm{N}$ & Dates of recording & Temperatures $\left({ }^{\circ} \mathrm{C}\right)$ \\
\hline \multicolumn{4}{|l|}{ C. barbara occurs allopatrically } \\
\hline Sevilla (Andalucía, Spain) & 7 & $6 / 8 / 2001$ & $38-41$ \\
\hline Córdoba (Andalucía Spain) & 5 & $6 / 9 / 2000$ & 34 \\
\hline Alcalar (Algarve, Portugal) & 10 & $23 / 8 / 1995$ & - \\
\hline Alvor (Algarve, Portugal) & 3 & 28/8/1995 & - \\
\hline Moura (Baixo Alentejo, Portugal) & 11 & $28 / 8 / 2001$ & $31-34$ \\
\hline Foz Côa (Beira Alta, Portugal) & 3 & $11 / 7 / 1999$ & 34 \\
\hline \multicolumn{4}{|l|}{ C. barbara occurs sympatrically } \\
\hline Portel (Alto Alentejo, Portugal) & 10 & $24 / 7$ and $10 / 8 / 2001$ & $31-35$ \\
\hline Sousel (Alto Alentejo, Portugal) & 11 & $8 / 9 / 2001$ & $33-35$ \\
\hline Monforte (Alto Alentejo, Portugal) & 6 & $22 / 7$ to $24 / 7 / 1995$ & - \\
\hline Crato (Alto Alentejo, Portugal) & 14 & $6 / 7$ to $8 / 7 / 1999 ; 15 / 7 / 1999 ; 1 / 8$ to $3 / 8 / 1999$ & $26-41$ \\
\hline Casalinho (Estremadura, Portugal) & 5 & $27 / 7 / 1995$ & - \\
\hline \multicolumn{4}{|l|}{ C. orni occurs allopatrically } \\
\hline Algeciras (Andalucía, Spain) & 10 & $5 / 8 / 2001$ & $31-34$ \\
\hline Alter-do-Chão (Alto Alentejo, Portugal) & 7 & 6 to $9 / 8 / 1997$ & $25-30$ \\
\hline Piedade (Arrábida, Estremadura, Portugal) & 10 & $19 / 7$ to $12 / 8 / 1995$ & - \\
\hline Monte-da-Caparica (Estremadura, Portugal) & 7 & 16 to $22 / 9 / 1997$ & $25-30$ \\
\hline \multicolumn{4}{|l|}{ C. orni occurs sympatrically } \\
\hline Sousel (Alto Alentejo, Portugal) & 11 & $27 / 6 / 2003$ & $27-30$ \\
\hline Monforte (Alto Alentejo, Portugal) & 16 & $25 / 7$ to $7 / 8 / 1997$ & $23-38$ \\
\hline Crato (Alto Alentejo, Portugal) & 8 & $27 / 6 / 2001$ & $24-26$ \\
\hline Arrábida (Estremadura, Portugal) & 4 & $18 / 8$ and $10 / 9 / 1997$ & 30 \\
\hline TOTAL & 158 & & \\
\hline
\end{tabular}



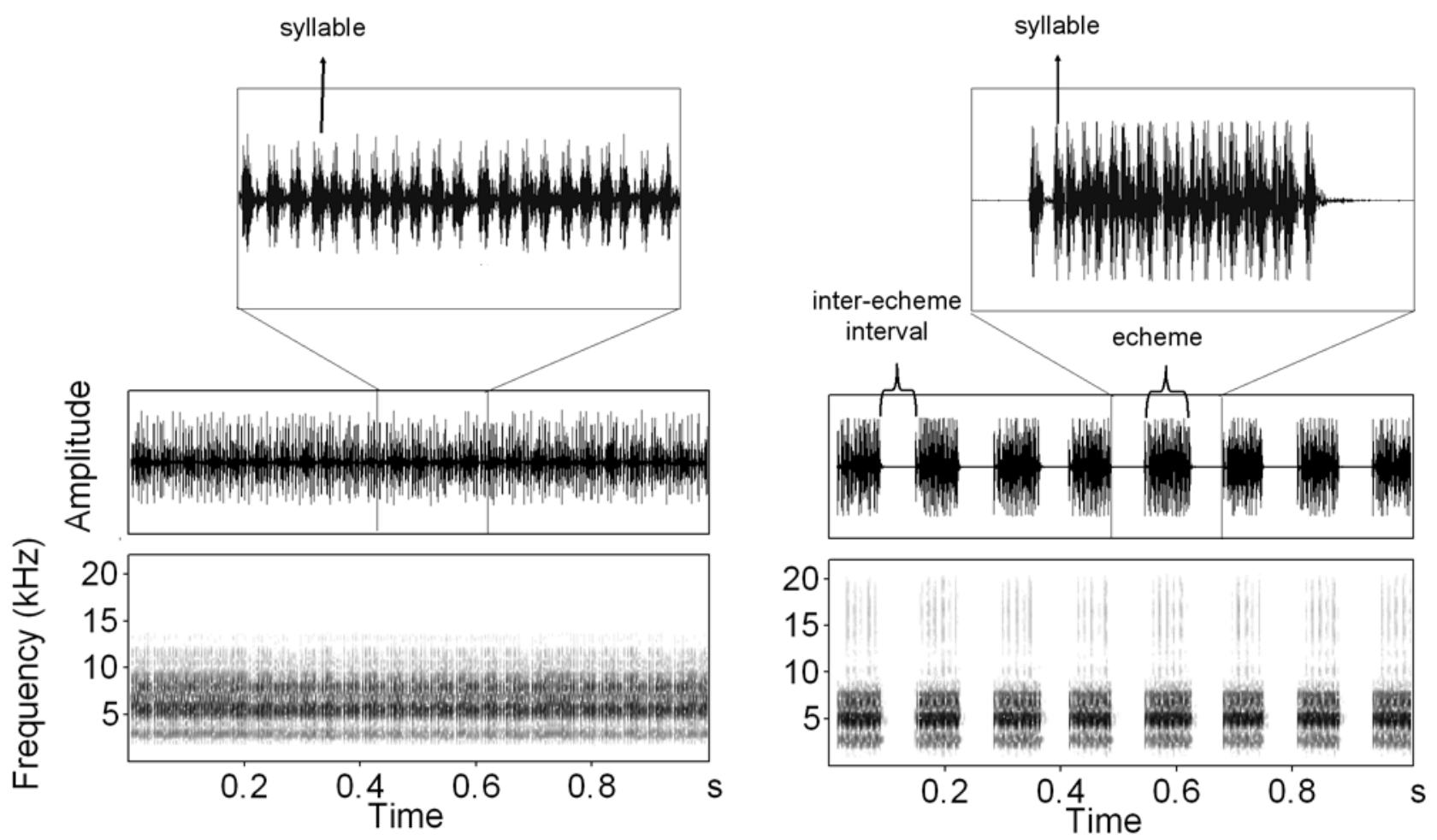

Fig. 2. Oscillograms (amplitude vs. time) and sonagrams (frequency vs. time) of the calling songs of Cicada barbara and C. orni.

tions of each variable to each discrimination function. All statistical analyses were carried out in SPSS Version 10.0.

\section{RESULTS}

Cicada barbara and C. orni differed significantly in every acoustic variable compared (Mann-Whitney, p < $0.001)$. The average values of frequency variables of $C$. orni were always lower than those of $C$. barbara. The peak frequency was $4709.8 \mathrm{~Hz} \pm 452.44$ (average \pm standard deviation) in C. orni and $6283.5 \pm 476.40$ in C. barbara. On the other hand, the syllable rate was on average higher in $C$. orni $(224.3 \pm 25.00)$ than, in $C$. barbara (201.4 \pm 18.78) (Table 2, Fig. 2). The syllable periods, derived from the syllable rates, ranged from 3.96 to 7.27 $\mathrm{ms}$ in C. barbara and from 3.84 to $6.72 \mathrm{~ms}$ in $C$. orni. The syllable rates for only one of the tymbals are half and the syllable periods double of these values.

The inter-individual coefficients of variation of the frequency variables varied from $6.24 \%$ to $20.85 \%$ in C. barbara and from $6.15 \%$ to $18.79 \%$ in C. orni. The syllable rate has a coefficient of variation of $9.35 \%$ in $C$. barbara and of $11.20 \%$ in C. orni. No significant difference between species was found in the coefficients of variation for the acoustic variables (Wilcoxon test, $p=0.859$ ). The inter-individual coefficients of variation for the temporal variables in $C$. orni were higher than the frequency variables and ranged from $24.90 \%$ to $68.38 \%$.

No significant differences in any of the acoustic variables were found between sympatric and allopatric populations of C. barbara (Mann-Whitney tests). In C. orni, only the minimum frequency differed significantly between sympatric and allopatric populations (MannWhitney test, $p=0.002$ ), with lower values when it occurred sympatrically than allopatrically (values for sympatric populations deviating more from those of $C$. barbara) (Fig. 3). This difference was not due to differences in temperature as no frequency variable significantly correlated with temperature. On the other hand, ambient temperature was found to be positively correlated with the syllable rate in both $C$. barbara and C. orni (Fig. 4) $\left(\mathrm{r}_{\mathrm{S}}=0.360, \mathrm{p}=0.006\right.$ for $C$. barbara and $\mathrm{r}_{\mathrm{S}}=0.714, \mathrm{p}$ $<0.001$ for $C$. orni). The correlation for C. barbara was only marginally significant after applying the Dunn-Sidák correction (critical $P$ value $=0.0057$ ), while that for $C$. orni was still strongly significant (critical $P$ value $=$ 0.0037). In C. orni, the echeme duration was negatively correlated $\left(\mathrm{r}_{\mathrm{S}}=-0.631, \mathrm{p}<0.001\right)$, the echeme rate was positively correlated $\left(\mathrm{r}_{\mathrm{S}}=0.574, \mathrm{p}<0.001\right)$ and the echeme period negatively correlated $\left(\mathrm{r}_{\mathrm{S}}=-0.574, \mathrm{p}<\right.$ $0.001)$ with temperature. The correlations between interecheme interval and temperature, and between the ratio echeme/interval and temperature were not significant $\left(\mathrm{r}_{\mathrm{S}}\right.$ $=0.030, \mathrm{p}=0.827$ and $\mathrm{r}_{\mathrm{S}}=-0.329, \mathrm{p}=0.012$, respectively) after applying the Dunn-Sidák correction.

In the PCA, the percentage of variation explained by the first four components was $95.3 \%$ (64.1\% by the first component alone, $80.0 \%$ by the first two and $89.2 \%$ by the first three). The component loadings were high for all variables in the first component (from 0.642 for band- 
TABLE 2. Average \pm standard deviation (SD), minimum (Min.), maximum (Max.) and coefficient of variation (CV, corrected for small size samples as in Sokal \& Rohlf (1981)) of the acoustic variables of the calling songs of Cicada barbara and C. orni recorded on the Iberian Peninsula.

\begin{tabular}{|c|c|c|c|c|c|c|c|c|c|c|}
\hline \multirow{2}{*}{ Acoustic variables } & \multicolumn{5}{|c|}{ C. barbara } & \multicolumn{5}{|c|}{ C. orni } \\
\hline & $\mathrm{N}$ & Average \pm SD & Min. & Max. & $\mathrm{CV}(\%)$ & $\mathrm{N}$ & Average \pm SD & Min. & Max. & $\mathrm{CV}(\%)$ \\
\hline Peak frequency $(\mathrm{Hz})$ & 85 & $6283.5 \pm 476.40$ & 5080 & 7660 & 7.60 & 73 & $4709.8 \pm 452.44$ & 3851 & 6199 & 9.64 \\
\hline Minimum frequency $(\mathrm{Hz})$ & 85 & $1830.7 \pm 337.53$ & 2150 & 4730 & 11.96 & 73 & $2125.5 \pm 372.79$ & 1583 & 3952 & 17.60 \\
\hline Maximum frequency (Hz) & 85 & $10840.5 \pm 1699.39$ & 7920 & 17910 & 15.72 & 73 & $9100.2 \pm 1185.43$ & 7239 & 13144 & 13.07 \\
\hline Bandwidth $(\mathrm{Hz})$ & 85 & $8006.2 \pm 1664.69$ & 5160 & 15330 & 20.85 & 73 & $6970.2 \pm 1305.07$ & 3626 & 11174 & 18.79 \\
\hline Quartile 25\% (Hz) & 85 & $5839.1 \pm 421.82$ & 4300 & 6460 & 7.24 & 73 & $4572.4 \pm 280.27$ & 3854 & 5011 & 6.15 \\
\hline Quartile $50 \%(\mathrm{~Hz})$ & 85 & $6665.2 \pm 414.62$ & 5680 & 7490 & 6.24 & 73 & $5472.0 . \pm 420.26$ & 4611 & 6280 & 7.71 \\
\hline Quartile $75 \%(\mathrm{~Hz})$ & 85 & $8543.2 \pm 715.16$ & 6460 & 9730 & 8.40 & 73 & $6894.6 \pm 517.50$ & 5405 & 8085 & 7.53 \\
\hline Quart75\%-Quart25\% (Hz) & 85 & $2704.1 \pm 452.18$ & 1300 & 3620 & 16.77 & 73 & $2321.9 \pm 363.30$ & 1242 & 3170 & 15.70 \\
\hline No. syllables/s & 82 & $201.4 \pm 18.78$ & 137.6 & 252.3 & 9.35 & 53 & $224.3 \pm 25.00$ & 148.7 & 260.3 & 11.20 \\
\hline No. Echemes/s & & & & & & 73 & $5.37 \pm 1.333$ & 2.38 & 7.49 & 24.90 \\
\hline Echeme duration (s) & & & & & & 73 & $0.078 \pm 0.0308$ & 0.039 & 0.207 & 39.58 \\
\hline Inter-echeme interval (s) & & & & & & 73 & $0.123 \pm 0.0720$ & 0.058 & 0.362 & 58.53 \\
\hline Echeme period (s) & & & & & & 73 & $0.201 \pm 0.0649$ & 0.134 & 0.420 & 32.34 \\
\hline Ratio echeme/interval & & & & & & 73 & $0.894 \pm 0.6093$ & 0.166 & 3.314 & 68.38 \\
\hline
\end{tabular}

width to 0.969 for quartile $75 \%$ in frequency variables and -0.484 for syllable rate). All the variables were significantly correlated, except for minimum frequency $v s$. bandwidth. There were no significant differences in the component scores of Component 1 and 2 between sympatrically and allopatrically occurring specimens of the same species (Mann-Whitney test, $\mathrm{p}>0.05$ ), but the sympatrically occurring specimens had a greater dispersion in the scatterplot (Fig. 5) than the allopatrically occurring ones in both species on both axis. This greater dispersion is probably the reason for the slight proximity observed between some sympatric specimens of one species and those of the other species.

DFA gave an overall correct classification rate of $62.96 \%$. Three functions were computed but only one was significant (Wilk's $\lambda=0.178, \mathrm{p}<0.0001$ ) and accounted for $97.6 \%$ of the variation. The structure matrix indicated that the frequency variables quartile $25 \%$, peak frequency, quartile $50 \%$, quartile $75 \%$ and minimum frequency were the most important in determining Function 1. The classification table (Table 3) showed that almost every $C$. barbara and $C$. orni individual where correctly classified to species, with the exception of three individuals (one sympatric C. barbara was classified as allopatric $C$. orni; one sympatric $C$. orni was classified as sympatric $C$. barbara; and one allopat- ric $C$. orni was classified as sympatric $C$. barbara). However, a substantial number of individuals of both allopatric and sympatric groups were misclassified. Individuals of $C$. orni that occurred sympatrically were mostly classified in the allopatric group. When crossvalidating, only $48.9 \%$ of the grouped samples were correctly classified, which indicates that this analysis did not discriminate between these groups.

When performing the Discriminant Analysis separately for each species, the discriminant function separating sympatric and allopatric $C$. barbara was significant (Wilk's $\lambda=0.828, \mathrm{p}=0.044$ ) and correctly classified $65.9 \%$ of the original samples and $53.7 \%$ of crossvalidated samples. The variables that were more highly correlated with the discriminant function were quartile $50 \%(0.621)$, peak frequency $(0.531)$, syllable rate $(-0.504)$ and minimum frequency $(0.493)$. When the Discriminant Analysis was applied to allopatric and sympatric $C$. orni, the discriminant function was not significant (Wilks' $\lambda=0.872, \mathrm{p}=0.479$, when the nine variables common to both species were used; and Wilks' $\lambda=$ $0.743, \mathrm{p}=0.260$, when all 14 variables were used).

\section{DISCUSSION}

The calling songs of Cicada barbara and C. orni are easily distinguished by the human ear since the first spe-

TABLE 3. Classification of groups using the Discriminant Function Analysis. Values are percentages of samples (individuals) in the actual group predicted to belong to each group. Number of samples (individuals) in parentheses.

\begin{tabular}{lcccc}
\hline \multirow{2}{*}{ Actual Group } & \multicolumn{4}{c}{ Predicted group membership } \\
\cline { 2 - 4 } & allopatric Cb & sympatric Cb & sympatric Co & allopatric Co \\
\hline allopatric C. barbara & $56.8 \%(21)$ & $43.2 \%(16)$ & $0.0 \%(0)$ & $0.0 \%(0)$ \\
sympatric C. barbara & $26.7 \%(12)$ & $71.1 \%(32)$ & $0.0 \%(0)$ & $2.2 \%(1)$ \\
sympatric C. orni & $0.0 \%(0)$ & $3.3 \%(1)$ & $76.7 \%(23)$ & $20.0 \%(6)$ \\
allopatric C. orni & $0.0 \%(0)$ & $4.3 \%(1)$ & $56.5 \%(13)$ & $39.1 \%(9)$ \\
\hline
\end{tabular}



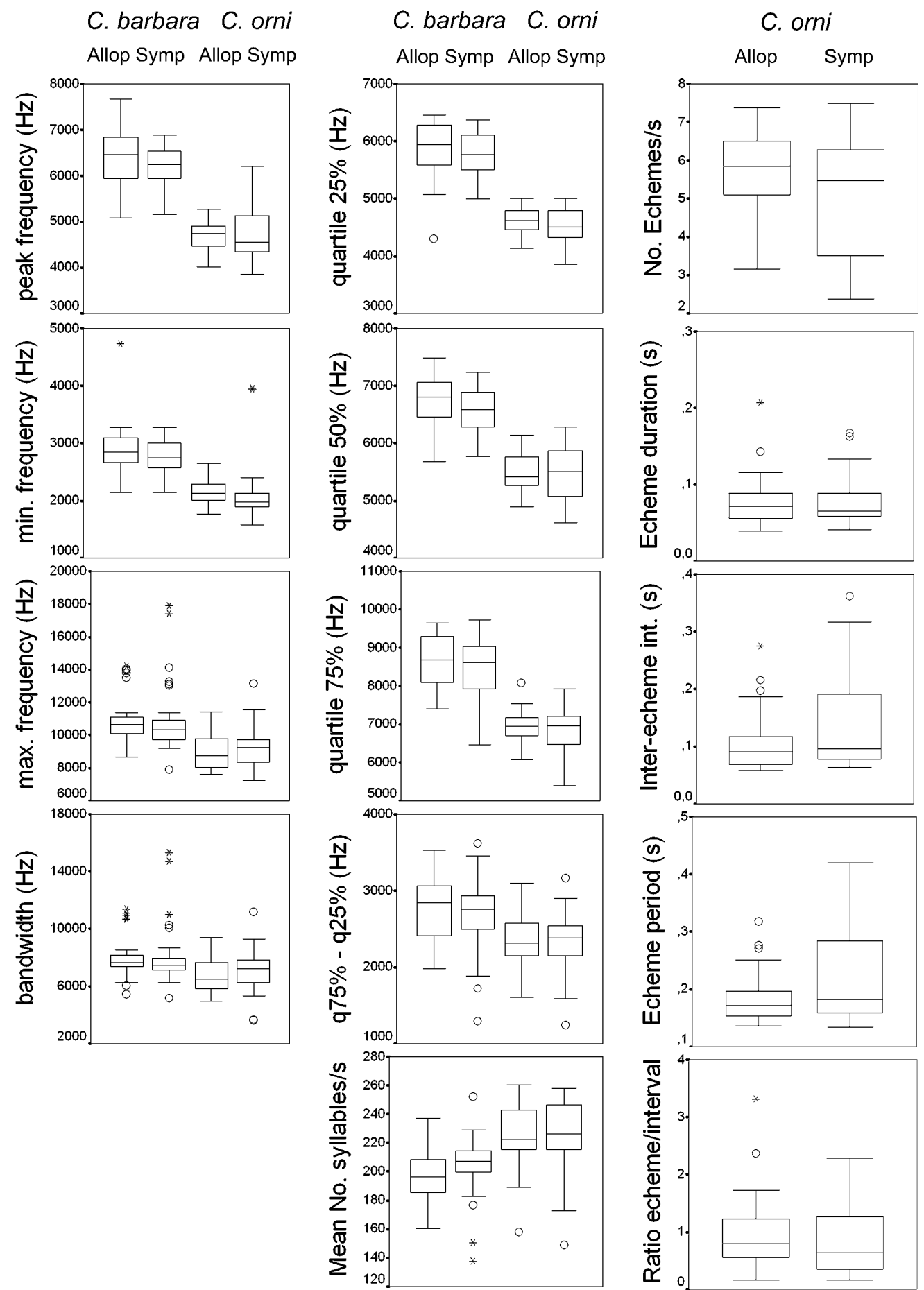

Fig. 3. Boxplots of the acoustic variables of the songs of Cicada barbara and C. orni occurring allopatrically (Allop) and sympatrically (Symp).

cies produces a continuous shrill and the latter a successive series of short shrills alternating with short pauses. At the acoustic frequency level these species are also generally distinct, $C$. barbara produces a higher peak frequency (average of $6.3 \mathrm{kHz}$ ) than C. orni (average of 4.7 $\mathrm{kHz}$ ), with a difference of more than $1 \mathrm{kHz}$ between the averages for each species. However, this is not a totally diagnostic characteristic because there is an overlap between species (see Fig. 3). In fact, some $C$. orni males produce a sound with a peak frequency above $6 \mathrm{kHz}$ and some $C$. barbara males a peak frequency as low as $5 \mathrm{kHz}$. Also the syllable rates of the two species overlap substantially, despite the average being significantly higher in $C$. orni than in $C$. barbara. In fact, the presence of a few specimens that, in some song variables, were similar to those of the other species caused the Principal Components Analysis and the Discriminant Function Analysis to indicate an incomplete separation between the species.

Differences in the frequency of the sounds are generally related to the size of the sound producing or resonator 
C. barbara

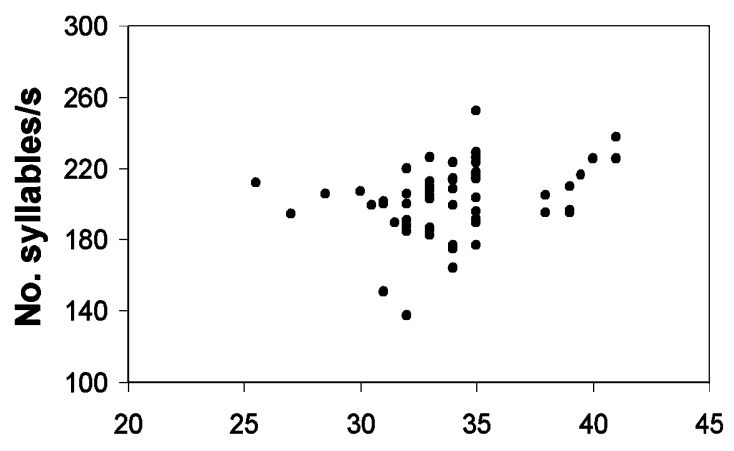

C. orni

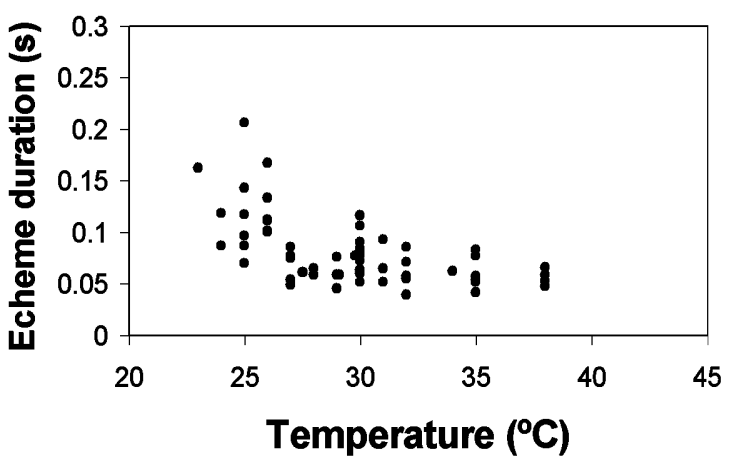

C. orni
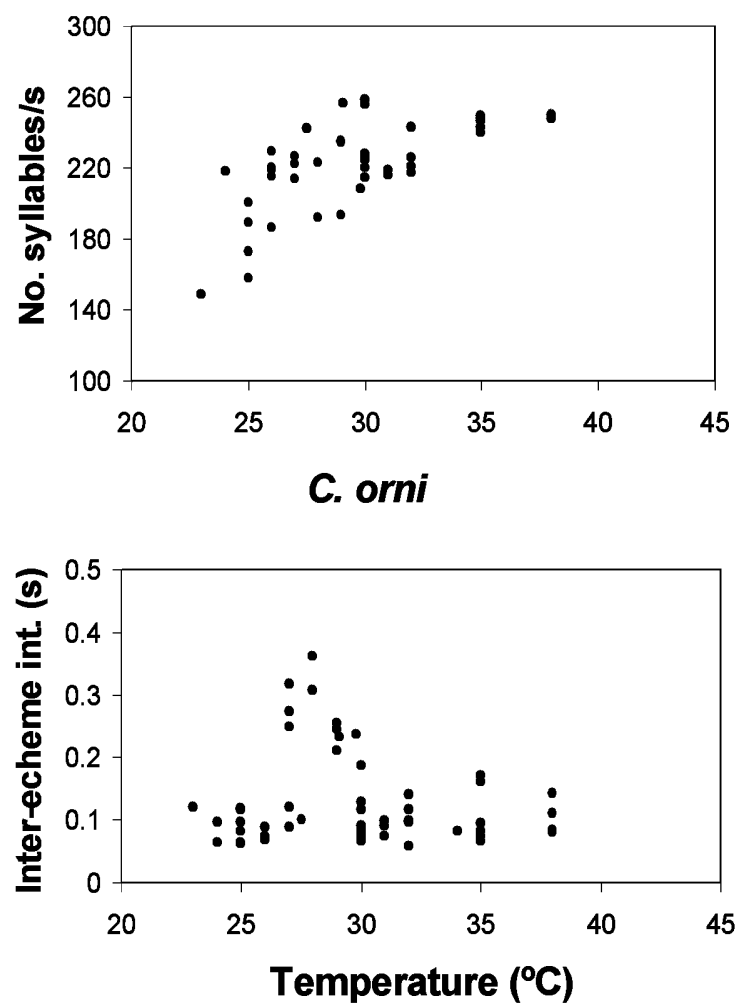

Fig. 4. Scatterplots of the number of syllables per second relative to temperature in Cicada barbara and C. orni and of both echeme duration and inter-echeme interval relative to temperature in C. orni.

organ (Young \& Josephson, 1983). A significant negative correlation is usually found between body length and the dominant song frequency in cicada species, with larger species producing lower dominant frequency songs (Bennet-Clark \& Young, 1994). This also appears to be the case in the pair of species analysed since $C$. barbara is usually smaller than C. orni (Ribeiro, 1998).

Variability in the frequency characteristics of calling songs of cicadas of these species was relatively low (coef-

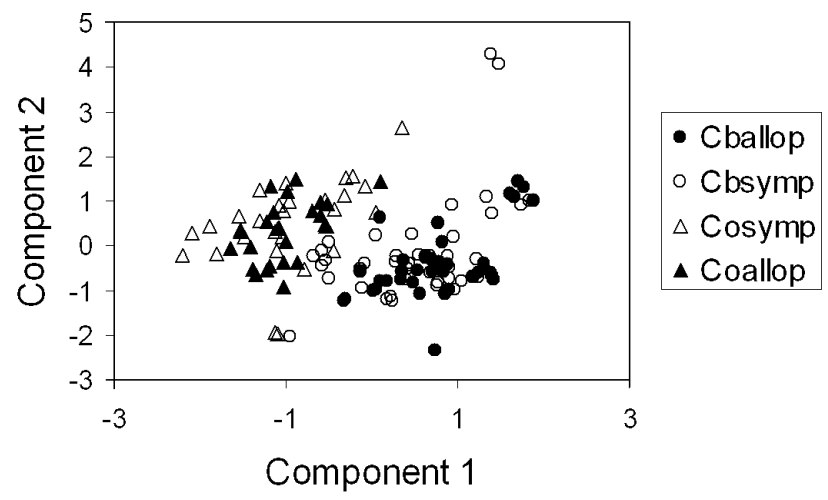

Fig. 5. Scores of the first two PCA components extracted from a data matrix, which was composed of 9 acoustic variables measured for 158 individuals of Cicada barbara $(\mathrm{Cb})$ and $C$. orni (Co) occurring allopatrically (allop) and sympatrically (symp). ficient of variation usually below 20\%), as expected since these characteristics are constrained by physical properties of the sound-producing organ. On the other hand, the variability of the gross-temporal characteristics in C. orni was high, as also found by Pinto-Juma et al. (2005). However, the fine-temporal characteristic of the songs of both species, the syllable rate, had similar coefficients of variation to the ones of the frequency variables. According to Gerhardt (1994), many female insects choose males whose signals have species-typical values of fine-temporal properties, such as pulse rate or duration. This would lead to stabilizing selection on these characteristics of the song.

However, the variability of the characteristics of each song should be analysed with caution, since the estimate of the variability is dependent on our ability to measure it, which might be different in scaling from the perceptual systems of the intended receivers (McGregor, 1991).

No cicadas with songs intermediate between $C$. barbara and $C$. orni were found in this study. All male cicadas were clearly identified by the gross-temporal differences in their songs ( $C$. barbara song is continuous and that of $C$. orni discontinuous). The overlap between species in some song variables is believed to be due to natural variation and not hybridization. Moreover, there was no evidence of character displacement in the acoustic variables studied. Only one acoustic variable (minimum frequency) was significantly different in allopatric and 
sympatric populations of $C$. orni showing a deviation from the $C$. barbara values. The multivariate analyses did not indicate any consistent differentiation between sympatric and allopatric populations at the acoustic level.

Also, previous morphometric work, based on the head, wings and male genitalia of $C$. barbara and $C$. orni, did not reveal differences between sympatric and allopatric populations (Ribeiro, 1998).

It is likely that the calling songs, which are most certainly part of the Specific-Mate Recognition Systems in these species, were already sufficiently differentiated before these species came into contact, and so, no hybridization occurred. In fact, at the mtDNA level, $C$. barbara and $C$. orni are highly divergent distinct lineages (Pinto-Juma et al., unpubl.). In terms of isolating mechanisms, the calling song is a prezygotic isolating mechanism that prevents hybridization between species. Since this mechanism was already differentiated before the species came into contact, acoustic character displacement was not necessary to ensure the correct selection by conspecific females. According to Gerhardt (1994), if the signals are already differentiated before the species come into contact, selection would only need to sharpen the selectivity of females, an aspect that should also be studied in these cicadas. C. barbara males can discriminate the frequency and temporal characteristics of their song and react preferentially to conspecific songs than to C. orni song (Fonseca \& Revez, 2002a), but the preferences of females are unknown.

The overlap in song frequencies between the two species could interfere with the communication in these species, particularly, C. barbara song could "mask" C. orni song since it is continuous and make the temporal characteristics of $C$. orni song more difficult to perceive by receivers. The fact that late in the summer season, $C$. orni is not or rarely found where they occur sympatrically while it remains abundant where it occurs on its own, might be a result of "acoustic competition". Different ecological adaptations could eventually reduce this competition. For instance, different singing positions in the vegetation of cicada species that occur sympatrically is described for C. orni/Lyristes (Claridge et al., 1979) and for C. orni/Tibicina haematodes (Sueur \& Aubin, 2003). Such segregation may also occur between $C$. orni and $C$. barbara, as observed qualitatively by Ribeiro (1998). Boulard (1982) records in Arrábida C. barbara singing on the seaward side and $C$. orni on the inland side of the mountain. However, in olive orchards at some sampling sites (e.g. Crato, Portel and Sousel) it was common to see males of both species singing on the same trunks or branches. A study of the micro-habitats occupied by these species (including their singing position on the trees) throughout the summer season (when only $C$. orni is present, when both species are present and when only $C$. barbara is present) is needed to test for ecological adaptations.

In order to exclude any potential effect geographic isolation, only Iberian Peninsula populations were analysed in this study. In fact, as detected previously, populations of these species from other areas differ from the Iberian Peninsula populations (Quartau et al., 1999, Pinto-Juma et al., 2005; Pinto-Juma et al., unpub.). The inter-echeme interval in $C$. orni song is longer in Greek than in Iberian Peninsula populations and the peak frequency is on average higher in Greece (Pinto-Juma et al., 2005). All frequency variables were higher in $C$. barbara from Morocco than from the Iberian Peninsula. It is most likely that these differences in $C$. orni populations are due to geographic distance, since the calling songs in France are similar to those in the Iberian Peninsula. In C. barbara, the differences could also be due to geographic isolation between North African and Iberian cicadas. Ecological factors, such as habitat and climatic conditions could be responsible for the direct or indirect selection of certain sound frequencies, specifically the lower frequencies found in both species on the Iberian Peninsula.

In the genus Cicada this is the only pair of species known to occur sympatrically. Other species like C. mordoganensis Boulard and C. cretensis Quartau \& Simões, which are present in the Aegean area, have a calling song very similar in temporal and frequency pattern to that of C. orni, which is also present in the same region (Simões et al., 2000; Quartau \& Simões, 2005), but they are not known to occur sympatrically with $C$. orni. It would be interesting to know if $C$. lodosi Boulard, which has a continuous song like C. barbara, but occurs in Turkey (Boulard, 1979), occurs sympatrically with any of the species with discontinuous songs.

The syllable rate increased significantly with temperature in $C$. orni, but only marginally significantly in $C$. barbara. In another study on more populations of $C$. barbara this correlation is significant (Pinto-Juma et al., in prep.). Also, Fonseca (1991) records a temperature dependent syllable period in C. barbara and an increase in syllable rate with temperature is described for other cicada species, such as Tettigeta argentata, Tettigeta josei and Tympanistalna gastrica (Fonseca \& Revez, 2002b).

In $C$. orni the echeme duration decreased significantly with increasing temperature and there was a very low non-significant correlation between the inter-echeme interval and temperature. In a previous study of one population of $C$. orni at Crato, several recordings per individual at different temperatures showed the same variation with temperature in echeme duration and interecheme interval as recorded in this study, though the significance values are marginal for echeme duration and below the critical 0.05 value for inter-echeme interval (echeme duration: $\mathrm{r}_{\mathrm{S}}=-0.248, \mathrm{p}=0.079$; inter-echeme interval: $r_{S}=0.339, p=0.015$ ) (Quartau et al., 2000). These differences could be due to a sampling effect or other factors. In fact, as reported before by Pinto-Juma et al. (2005), the population at Sousel had longer interecheme intervals than other $C$. orni populations, which is not a temperature dependence outcome, since longer intervals would be expected at higher temperatures (Quartau et al., 2000) and Sousel individuals were sampled at temperatures ranging from only $27^{\circ} \mathrm{C}$ to $30^{\circ} \mathrm{C}$. Excluding this population, the results in terms of correla- 
tions remained the same (inter-echeme interval positively but not significantly correlated with temperature). The conditions under which $C$. orni population at Sousel were recorded might have been unusual and not detected by the researchers. Nevertheless, Sousel is an area where $C$. orni and $C$. barbara occur sympatrically, and thus, a character displacement might be occurring in which longer silent pauses occur between echemes in the song of $C$. orni, making it more different from the song of C. barbara, which has no silent pauses. However, this hypothesis is not consistent with the findings for other areas where these species occur sympatrically. Furthermore, some cicadas from Piedade, where $C$. orni occurs allopatrically have also long inter-echeme intervals compared to other populations (Pinto-Juma et al., 2005). However, this is also inconclusive since the environment temperature was not taken at the time of the recording in this population.

ACKNOWLEDGEMENTS. We are grateful to G. André and P. Simões (Faculdade de Ciências de Lisboa, Portugal) for help in the field. We also thank M. Ribeiro, T. Fernandes and J. Sueur for some of the recordings. J. Sueur gave important contribution in the discussion of results. We thank one referee and the language editor for their important contributions in improving the manuscript. This study was financially supported by Fundação para a Ciência e a Tecnologia (F.C.T., Portugal; PhD grants SFRH/BD/1027/2000 and PRAXIS BD/18229/98).

\section{REFERENCES}

Bennet-Clark H.C. \& Young D. 1994: The scaling of song frequency in cicadas. J. Exp. Biol. 191: 291-294.

Boulard M. 1979: Cigales du genre Cicada Linne, originaires de Turquie (Hom. Cicadidae). Türk. Bit. Kor. Derg. 3(2): 67-74.

Boulard M. 1982: Les cigales du Portugal, contribution à leur étude (Hom. Cicadidae). Annls. Soc. Entomol. Fr. 18: 181-198.

Boulard M. 1995: Postures de cymbalisation et cartes d'identité acoustique de cigales. 1. Généralités et espéces méditerranéennes (Homoptera, Cicadoidea). EPHE Biol. Evol. Insects 7/8: 14-25.

Claridge M.F., Wilson M.R. \& Singhrao J.S. 1979: The songs and calling sites of two European cicadas. Ecol. Entomol. 4: 225-229.

Cocroft R.B. \& Pogue M. 1996: Social behavior and communication in the Neotropical cicada Fidicina mannifera (Fabricius) (Homoptera: Cicadidae). J. Kansas Entomol. Soc. 69(4): 85-97.

Cooley J.R. \& Marshall D.C. 2001: Sexual signaling in periodical cicadas, Magicicada spp. (Hemiptera: Cicadidae). Behaviour 138: 827-855.

Daws A.G., Hennig R.M. \& Young D. 1997: Phonotaxis in the cicadas Cystosoma saundersii and Cyclochila australasiae. Bioacoustics 7: 173-188.

Dobzhansky T. 1951: Genetics and the Origin of Species. 3rd ed. Columbia University Press, New York.

Doolan J.M. 1981: Male spacing and the influence of female courtship behaviour in the bladder cicada, Cystosoma saundersii Westwood. Behav. Ecol. Sociobiol. 9: 269-276.

Dyтнам C. 2003: Choosing and Using Statistics, a Biologist's Guide. 2nd ed. Blackwell, Science, Oxford, 248 pp.

FonseCA P.J. 1991: Characteristics of the acoustic signals in nine species of cicadas (Homoptera, Cicadidae). Bioacoustics 3: 173-192.
FonseCa P.J. 1994: Acoustic Communication in Cicadas (Homoptera; Cicadoidea): Sound Production and Sound Reception. Thesis, Faculty of Sciences, University of Lisbon, $282 \mathrm{pp}$.

Fonseca P.J. \& Revez M.A. 2002a: Song discrimination by male cicadas Cicada barbara lusitanica (Homoptera, Cicadidae). $J$. Exp. Biol. 205: 1285-1292.

FonseCA P.J. \& Revez M.A. 2002b: Temperature dependence of cicada songs (Homoptera, Cicadoidea). J. Comp. Physiol. (A) 187: 971-976.

Gerhardt H.C. 1994: Selective responsiveness to long-range acoustic signals in insects and anurans. Am. Zool. 34: 706-714.

Marshall D.C. \& Cooley J.R. 2000: Reproductive character displacement and speciation in periodical cicadas, with description of a new species, 13-year Magicicada neotredecim. Evolution 54: 1313-1325.

MAYR E. 1948: The bearing of the new systematics on genetical problems. The nature of species. Adv. Genet. 2: 205-237.

MAYr E. 1963: Animal Species and Evolution. Harvard University Press, Cambridge, Massachussetts, 797 pp.

McGregor P.K. 1991: The singer and the song: on the receiving end of bird song. Biol. Rev. 66: 57-81.

Paterson H.E.H. 1985: The recognition concept of species. In Vrba E.S. (ed.): Species and Speciation. Transvaal Museum Monograph No. 4, Transvaal Museum, Pretoria, pp. 21-29.

Pinto-Juma G., Simões P.C., Seabra S.G. \& Quartau J.A. 2005: Calling song structure and geographic variation in Cicada orni Linnaeus (Hemiptera: Cicadidae). Zool. Stud. 44(1): 81-94.

Popov A.V. 1975: The structure of the tymbals and the characteristics of the sound signals in singing cicadas (Homoptera, Cicadidae) in the southern regions of the USSR. Entomol. Rev. 54(2): 7-35.

Puissant S. \& Sueur J. 2001: Contribution à l'étude des cigales de Corse (Hemiptera, Cicadidae). Bull. Soc. Entomol. Fr. 106: 429-436.

QuARTAU J.A. 1988: A numerical taxonomic analysis of interspecific morphological differences in two closely related species of Cicada (Homoptera, Cicadidae) in Portugal. Great Basin Nat. Mem. 12: 171-181.

Quartau J.A. 1995: Cigarras-esses insectos quase desconhecidos. Correio Natur. 19: 33-38.

Quartau J.A. \& FonseCa P.J. 1988: An annotated check-list of the species of cicadas known to occur in Portugal (Homoptera: Cicadoidea). In Vidano C. \& Arzone A. (eds): Proceedings of the 6th Auchenorrhyncha Meeting, Turin, Italy, September 7-11, 1987. Consiglio Nazionale delle Ricerche, Turin, pp. 367-375.

Quartau J.A. \& Rebelo M.T. 1994: Sinais acústicos em Cicadidae e Cicadellidae (Homoptera, Auchenorryncha) que ocorrem em Portugal. In Almada V. \& Correia R. (eds): Actas do I Congresso Nacional de Etologia, Lisboa 28, 29 e 30 de Novembro de 1991. Instituto Superior de Psicologia Aplicada, Lisboa, pp. 137-142.

Quartau J.A. \& Simões P.C. 2003: Bioacoustic and morphological differentiation in two allopatric species of the genus Tibicina Amyot (Hemiptera: Cicadoidea) in Portugal. D. Entomol. Z. 50: 113-119.

Quartau J.A. \& Simões P.C. 2005: Cicada cretensis sp. n. (Hemiptera, Cicadidae) from southern Greece. Biologia 60: 489-494.

Quartau J.A., Rebelo M.T., Simões P.C., Fernandes T.M., Claridge M.F., Drosopoulos S. \& Morgan J.C. 1999: Acoustic signals of populations of Cicada orni L. in Portugal and Greece (Homoptera: Auchenorrhyncha: Cicadomorpha: Cicadidae). Reichenbachia 33(8): 71-80. 
Quartau J.A., Seabra S. \& Sanborn A. 2000: Effect of ambient air temperature on the calling song of Cicada orni Linnaeus, 1758 (Hemiptera: Cicadidae) in Portugal. Acta Zool. Cracov. 43(3-4): 193-198.

RibeIro M. 1998: Diferenciação em duas espécies gémeas do género Cicada L. (Insecta, Homoptera, Cicadoidea): Cicada orni L. e Cicada barbara (Stal). Thesis, Faculty of Sciences, University of Lisbon, $70 \mathrm{pp}$.

SchedL W. 1973: Zur Verbreitung, Bionomie und Ökologie der Singzikaden (Homoptera: Auchenorrhyncha, Cicadidae) der Ostalpen und ihrer benachbarten Gebiete. Ber. Nat. Med. Ver. Innsbruck 60: 79-94.

SCHEDL W. 1999: Contribution to the singing cicadas of Israel and adjacent countries (Homoptera, Auchenorrhyncha: Cicadidae et Tibicinidae). Linzer Biol. Beitr. 31: 823-837.

Simões P.C., Boulard M.M., Rebelo M.T., Drosopoulos S., Claridge M.F., Morgan J.C. \& Quartau J.A. 2000: Differences in the male calling songs of two sibling species of Cicada (Hemiptera: Cicadoidea) in Greece. Eur. J. Entomol. 97: 437-440.

Sokal R.R. \& Rholf F.J. 1981: Biometry. The Principles and Practice of Statistics in Biological Research. W.H. Freeman, New York, $859 \mathrm{pp}$.
Specht R. 2002: Avisoft-SASLab Pro- Sound analysis and synthesis laboratory. Version 4.1d, Berlin.

Sueur J. \& Aubin T. 2003: Is microhabitat segregation between two cicada species (Tibicina haematodes and Cicada orni) due to calling song propagation constraints? Naturwissenschaften 90: $322-326$.

Sueur J. \& Aubin T. 2004: Acoustic signals in cicada courtship behaviour (order Hemiptera, genus Tibicina). J. Zool. (Lond.) 262: 217-224.

VILLET M. 1992: Responses of free-living cicadas (Homoptera: Cicadidae) to broadcasts of cicada songs. J. Entomol. Soc. Sth. Afr. 55(1): 93-97.

VILLET M. 1995: Intraspecific variability in SMRS signals: some causes and implications in acoustic signaling systems. In Lambert D.M. \& Spencer H.G. (eds): Speciation and the Recognition Concept. Theory and Applications. The John Hopkins University Press, Baltimore and London, pp. 422-439.

YounG D. \& JosEPHSON R.K. 1983: Pure-tone songs in cicadas with special reference to the genus Magicicada. J. Comp. Physiol. 152: 197-207.

Received January 19, 2006; revised and accepted May 10, 2006 